\title{
Unresectable Gastric Adenocarcinoma
}

National Cancer Institute

\section{Source}

National Cancer Institute. Unresectable Gastric Adenocarcinoma. NCI Thesaurus. Code C154221.

A gastric adenocarcinoma that is not amenable to surgical resection. 